\title{
The ICES Census of the Fishes Workshop
}

Colin Bannister

Centre for Eniironment, Fisheries, and Aquaculture Science - Lowestoft LK

\begin{abstract}
In the summer of 1997, while I was visiting at Woods Hole, Jesse Ausubel, representing the Sloan Foundation, asked me to approach ICES (International Council for the Exploration of the Sea) for help with the Census of the Fishes project. I was then chair of the principal science co-ordinating committee in ICES, and I agreed to take the idea forward.
\end{abstract}

\begin{abstract}
Why ICES ?
ICES was the first inter-governmental scientific body. It was founded in 1902 to promote the study of the seas, principally in the North Atlantic, and it now also advises various bodies responsible for managing fisheries and the marine environment in the North Atlantic. ICES has no research funds, but maintains a Secretariat in Copenhagen, with co-ordinating, data-base and publishing functions. At the ICES Annual Science Conference (ASC) each fall, scientists give papers, discuss new ideas, and propose member country participation in programes, workshops, and working groups. ICES therefore has the infrastructure to discuss the scientific, technical and logistic aspects of a project like the Census, and to co-ordinate input to it, provided this is agreed by the national delegates and fundholders.
\end{abstract}

\section{The ICES Planning Group}

The ICES specialists in fisheries, biological oceanography, and acoustics are both visionary and practical. So, at the ASC in fall 1997 in Baltimore, I convened an informal expert group to discuss scientific goals for a Census project. After an hour I was convinced that we could define genuine global and regional goals for a Census project, and that ICES could play a role if member countries agreed. I engineered approval for an ICES Census of the Fishes Planning Group and a Census Workshop to be financed from Sloan funds.

\section{The Workshop}

The ICES / Sloan Foundation Census of the Fishes Workshop was held on 20-22 April 1998 at the Southampton Oceanography Centre, UK, hosted by Professor John Shepherd. Over forty invited scientists from Europe, USA and Canada enjoyed three days of brainstorming in plenum and in sub-groups. In an ambience which fittingly recalled the Challenger, we were also able to attend a memorable dinner on the gun-deck of the 19th century iron-clad HMS Warrior, moored in the naval harbor at Portsmouth, just across from HMS Victory. Dr. Pat Hargreaves shared the task of developing a transcript, and my report to ICES (ICES CM 1998/G:11. Report of the ICES Planning Group on the Census of the Fishes).

\section{Point of Departure}

The Planning Group primed the Workshop by reflecting on what is not known about the oceans, and by noting what technology is available but not used in the study of fisheries and food chains. Beyond a few intensively studied areas, our knowledge of the species, processes and rates in the marine food chain is in reality quite limited, especially the intermediate links in the open ocean and in the mid and deep waters. In some shelf seas we know what animals are caught by highly selective nets or dredges, but further offshore in deep water, and especially in mid-water and in the Southern Hemisphere, our sketchy knowledge still harks back to the widely spaced samples collected by a few discrete expeditions. For animals which are too large, too small, too fast, or too fragile to be caught in nets we know almost nothing, except for a few observations from manned submersibles. The gaps range from the large fishes and squids to myctophids, euphausiids and even to small plankton. Squid, which have large basin-scale patterns of distribution and migration, are particularly important, forming critical links in the food chain between oceanic fish, birds, and mammals, and potentially capable of replacing over-exploited fish stocks in some areas, yet we are only just now including them in 
quantitative ocean studies. Some of these understudied groups could contribute major fractions to the total global biomass, and a Census could change our perception and understanding of the entire ocean biomass pyramid.

On the technological front it was an eye-opener to hear engineers and acoustic experts list the jargon words which surely whet the appetite for the future: lidar, acoustic tomography, multi-frequency sonars, multi-beam acoustics, sub-meter scale sensors, enhanced side-scan sonar, bio-optics, satellite imaging and sensing.

With these challenging thoughts in mind, the Workshop distilled the following questions:

- What lives in the oceans?

- Where does it live?

- How much is there?

- What is the pattern of diversity, and how does it vary?

- What are the interactions and processes?

- What control systems operate?

- How much fine-scale resolution is required?

- What can the present tell us about changes since the past?

- Is the ocean healthy?

- How much change can it assimilate?

- Do observed responses reflect universal mechanisms?

- Is global warming real?

- What predictions can be made about the future?

- What baseline is required for assessing change in the future?

- What will we need to know over the next 10 to100 years?

\section{The Way Forward}

The workshop concluded that a global "Grand Challenge to Census Marine Life" was useful, attractive, and potentially feasible, but would be a major long term undertaking. The suggested primary aim is to make a first global synoptic view of marine living resources. This will be an extended snapshot of the structure and function of the marine ecosystem, as a baseline for comparison with the past and the future. This snapshot will take several years to collect, and sampling must take into account seasonal and interannual variability. The horizontal scale should range from coastal waters to the shelf, slope and open ocean, from pole to tropic. The vertical scale should range from surface productivity, to the deep sea pelagic zone, and the least known benthic layer. As a living resource ana$\log$ of such as the World Ocean Circulation Experiment (WOCE), or the Global Ocean Observing System (GOOS), the Census could harness and develop new remote sensing, acoustic and optical technology to make multiple measurements in the scarcely sampled open oceans, for comparison with the better studied but still imperfectly known shelf seas. It could couple extensive low intensity sampling with intensive detailed sampling at selected stations and depths. Bio-geographic provinces could be the primary choice of sampling strata, although these are not absolute in character because phytoplankton are affected by climate and latitude, zooplankton are affected by ocean circulation and fronts, and benthic populations are influenced by depth and the nature of the sea floor.

\section{The benefits}

Given uncertainties about the long term effects of fisheries exploitation, contaminants, and climate change, the above study could establish baseline information on biodiversity and biomass of the higher trophic levels, before these are further perturbed, and could promote the use of models to predict the impacts of climatic change and anthropogenic disturbance. As the North Atlantic is already well known and extensively perturbed, it could offer critical tests for the scientific value, technical feasibility and design of the Census, and hence should be of particular interest to ICES.

\section{Primary objectives}

The primary objective should be to quantify the timespace distribution of numbers and biomass of nektonic species of fish and crustacea of a minimum size of $2 \mathrm{~cm}$ up to $100 \mathrm{~cm}$, but also cephalopods, salps, siphonophores, cetaceans, sea birds, and macrobenthos. The study of higher trophic levels will require ecological data on primary production; biological, chemical, and physical oceanography; and data on commercial fisheries. Biological resolution should be at the level of dominant species, since this is the interface where evolution, ecology, environment, and anthropogenic factors meet. Significant constraints will be imposed by available identification knowledge, however, so the resolution obtainable in less well studied areas may be at the aggregated level of functional groups or assemblages. The distribution of number and biomass will measure diversity but should also identify linkages, functions, and processes, so that we can understand enough to measure changes, or to understand the implications of change. Emergent properties such as size spectra, the demersal/pelagic biomass ratio, or the ratio of other species groups, could all be valuable. It may be possible to use Census data to test the predictions from a range of a priori models. 


\section{Sampling strategies}

Sampling gear, optical and acoustic technology, and species identification skills, will require standardization and calibration. Taxonomists will use existing archives of specimens, and taxonomic databases, but will need to develop new ones. Participants agreed on the need for repeatable and replicate sampling and calibration techniques, and agreed that it could be necessary to extend taxonomic expertise by developing training programs. There may be scope for using molecular genetics to assist with the identification of difficult groups, or their unknown relatives, such as copepods. A particular role for ICES could be to standardise protocols for methods giving repeatable results. It may be possible to place technology packages on commercial ships and aircraft but they will not cover all areas. Participants agreed that a data management policy is required, based on existing and new databases.

\section{Follow up}

This is a brief summary of a very large body of information and views which were compiled and archived by the Workshop for wider use. A Census project would involve several major phases, including planning, tech- nology evaluation, development and trial deployments, a pilot project, and an extended global project. This illustrates just how large a comprehensive Census of Marine Life project will be. A Program Office will be essential, with an appropriate mission statement, objectives, target dates, and a web site.

As an immediate follow up, the ICES Planning Group reported to the ICES Annual Science Conference in fall 1998. It proposed that the Planning Group should continue to work to develop specific implementation plans, including a North Atlantic Pilot Program, and individual scientific and technical Study and Workshops. For a variety of reasons the ICES Council did not feel able to take this forward at this time, but it will keep abreast of current developments through its USA delegate. I have now ended my term as the ICES scientific co-ordinator, but I remain convinced that with the strong support of the Sloan Foundation the Census will become a reality, and ICES will hopefully consider again how it may contribute further.

बr
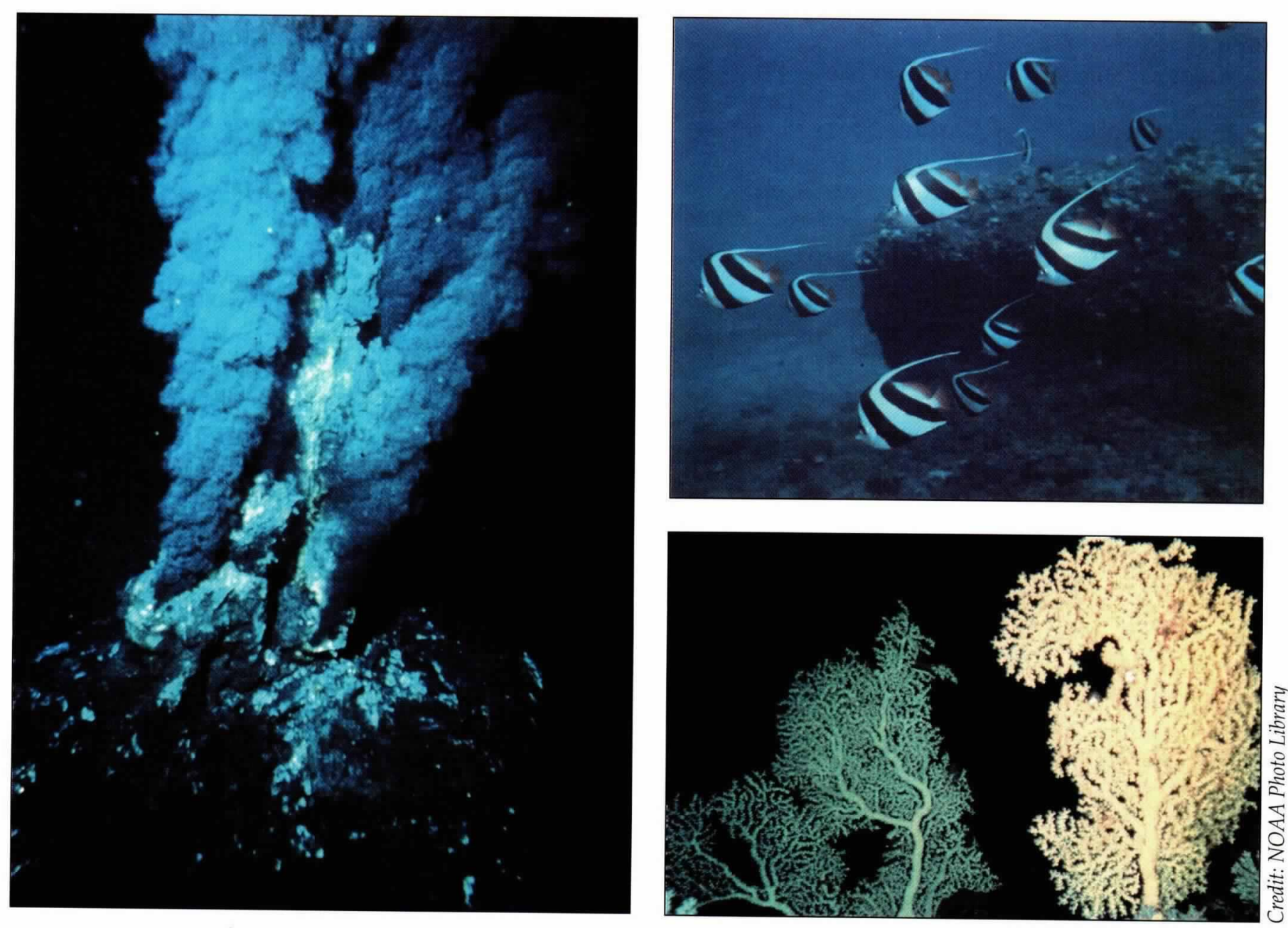